\title{
A promoter polymorphism of the CYP27B1 gene is associated with Addison's disease, Hashimoto's thyroiditis, Graves' disease and type 1 diabetes mellitus in Germans
}

\author{
Elizabeth Ramos Lopez, Oliver Zwermann ${ }^{1}$, Maria Segni ${ }^{2}$, Gesine Meyer, Martin Reincke ${ }^{1}$, Jochen Seissler ${ }^{3}$, \\ Jürgen Herwig, Klaus-H Usadel and Klaus Badenhoop \\ Department of Internal Medicine I, Division of Endocrinology, University Hospital Frankfurt, Frankfurt am Main, Germany, ${ }^{1}$ Department of Internal \\ Medicine II, Division of Gastroenterology, Hepatology and Endocrinology, University Hospital Freiburg, Freiburg, Germany, ${ }^{2}$ Department of Pediatrics \\ (MS, AMP), Endocrinology Unit, University "La Sapienza", Rome, Italy and 3German Diabetes Research Institute, University Hospital Düsseldorf, \\ Düsseldorf, Germany
}

(Correspondence should be addressed to K Badenhoop, Department of Internal Medicine I, Division of Endocrinology, University Hospital Frankfurt, Theodor-Stern-Kai 7, D-60590 Frankfurt am Main, Germany; Email: badenhoop@em.uni-frankfurt.de)

\begin{abstract}
Background: CYP27B1 hydroxylase catalyzes the conversion of 25 hydroxyvitamin $\mathrm{D}_{3}\left(25 \mathrm{OHD}_{3}\right)$ to $1,25(\mathrm{OH})_{2} \mathrm{D}_{3}$, the most active natural vitamin $\mathrm{D}$ metabolite, which plays a role in the regulation of immunity and cell proliferation. We therefore investigated two single nucleotide polymorphisms in the CYP27B1 hydroxylase gene for an association with Addison's disease, Hashimoto's thyroiditis, Graves' disease and type 1 diabetes mellitus.

Methods: Patients with Addison's disease $(n=124)$, Hashimoto's thyroiditis $(n=139)$, Graves' disease $(n=334)$, type 1 diabetes mellitus $(n=252)$ and healthy controls $(n=320)$ were genotyped for the promoter $(-1260) \mathrm{C} / \mathrm{A}$ polymorphism and for the intron $6(+2838) \mathrm{C} / \mathrm{T}$ polymorphism of the CYP27B1 gene. Patients and controls were compared using genotype-wise and allele-wise $X^{2}$ testing.

Results: A significant association was found between allelic variation of the promoter $(-1260) \mathrm{C} / \mathrm{A}$ polymorphism and Addison's disease, Hashimoto's thyroiditis, Graves' disease and type 1 diabetes mellitus $(P=0.0062, P=0.0173, P=0.0094$ and $P=0.0028$ respectively $)$. Significant differences were also observed for the intron $6(+2838) \mathrm{C} / \mathrm{T}$ polymorphism $(P=0.0058)$ in Hashimoto's thyroiditis but not for the other autoimmune endocrine diseases.

Conclusions: The CYP27B1 promoter $(-1260)$ C/A polymorphism appears to be associated with endocrine autoimmune diseases but the CYP27B1 intron $6(+2838) \mathrm{C} / \mathrm{T}$ polymorphism appears to be associated only with Hashimoto's thyroiditis. These results imply a regulatory difference of the CYP27B1 hydroxylase to predispose to endocrine autoimmunity.
\end{abstract}

European Journal of Endocrinology 151 193-197

\section{Introduction}

CYP27B1 (25-hydroxyvitamin $\mathrm{D}_{3}-1 \alpha$-hydroxylase) is a mitochondrial P450 enzyme (1), which catalyzes the conversion of 25-hydroxyvitamin $\mathrm{D}_{3}$ to $1,25(\mathrm{OH})_{2} \mathrm{D}_{3}$, the most active natural vitamin $\mathrm{D}$ metabolite. It is the key enzyme determining the rate of $1,25(\mathrm{OH})_{2} \mathrm{D}_{3}$ production. Renal (2) and extrarenal tissues express CYP27B1 suggesting endocrine as well as para- und autocrine functions of this enzyme (3). Mutations within the CYP27B1 gene, which impair CYP27B1 hydroxylase activity and cause vitamin D-dependent rickets, have been described (4). The CYP27B1 gene is located on chromosome 12q.13.1-13.3, ten megabases centromeric of the vitamin $\mathrm{D}$ receptor (VDR) locus (5).
The secosteroid $1,25(\mathrm{OH})_{2} \mathrm{D}_{3}$ acts via the nuclear VDR, and effectively prevents the development of autoimmune diabetes mellitus (6) and autoimmune thyroiditis in animal models (7). In addition, disorders such as experimentally induced autoimmune encephalitis can be favorably influenced by administering $1,25(\mathrm{OH})_{2} \mathrm{D}_{3}(8)$.

This secosteroid exerts its immunomodulatory actions by inhibiting human leukocyte antigen (HLA) class II expression on endocrine cells (9), T cell proliferation and secretion of inflammatory cytokines that are thought to act as mediators in autoimmune tissue destruction (10). Additionally $1,25(\mathrm{OH})_{2} \mathrm{D}_{3}$ inhibits differentiation and maturation of cultured human monocyte-derived dendritic cells into potent antigen presenting cells (11). Incubation of bone marrow cells 
with an analog of $1,25(\mathrm{OH})_{2} \mathrm{D}_{3}$ resulted in a population of immature dendritic cells unable to produce high levels of interleukin-12 (12).

Allelic variations within the VDR gene have been implicated in mediating susceptibility to endocrine autoimmune disease (13-15). In different populations a genetic association of the HLA system with these autoimmune diseases has been found (16-19). In addition, polymorphisms within the cytotoxic T lymphocyte antigen 4 (CTLA-4) gene as well as variations within the VDR gene have been shown to confer susceptibility to these diseases (20-22).

Given the shared genetic susceptibility among endocrine autoimmune disorders and the association of VDR variants with autoimmune disease, we investigated the distribution of two polymorphisms, one in the promoter region and another in intron 6 of the CYP27B1 hydroxylase gene in patients with Addison's disease, thyroid autoimmune disease and type 1 diabetes mellitus compared with healthy controls. The promoter region polymorphism was selected because of the possible role in the expression of the gene. The intron 6 polymorphism was studied in order to confirm our findings of an earlier publication (23).

\section{Subjects and methods}

\section{Subjects}

All patients were recruited from the endocrine outpatient clinics at the University Hospitals of Frankfurt am Main, Freiburg and Düsseldorf, Germany.

Addison's disease was diagnosed by primary adrenocortical insufficiency without evidence of tuberculosis or adrenoleukodystropy. Adrenal autoantibodies were detected with indirect immunofluorescence on cryostat sections; these were confirmed to be directed against 21-hydroxylase in a subgroup of patients by radioimmunoassay.

Thirty-three patients $(26.4 \%)$ suffered either from thyroid autoimmune disease or were thyroid autoantibody positive as part of a polyglandular syndrome type 2 and only two patients were also affected by type 1 diabetes mellitus, also known as Schmidt's syndrome. The age of onset varied from 15 to 42 years and no neurological deficits could be detected.

Hashimoto's thyroiditis was diagnosed by positive thyroglobulin $(\mathrm{Tg})$ and/or thyroid peroxidase antibodies, reduced echogenicity on thyroid ultrasound, and normal or elevated thyrotropin (TSH) levels.

Graves' disease diagnosis rested on autoimmune hyperthyroidism with TSH receptor antibodies and/or ophthalmopathy.

Type 1 diabetes mellitus was diagnosed according to World Health Organization criteria. The median age at diagnosis was 10.5 years (range $1-37$ years).

Healthy controls $(n=320)$, which were collected at random from the population in Frankfurt am Main,
Germany, had no family history of type 1 diabetes mellitus, Hashimoto's thyroiditis, Graves' disease or Addison's disease. Although the adrenal function of the controls was not formally assessed, they had normal thyroid function and were thyroid autoantibody negative. All individuals were of Caucasian origin. The study protocol was approved by the Ethics Committee of the University Hospital, Frankfurt am Main and written informed consent was obtained from all patients and controls.

\section{Genotype analysis}

DNA was extracted from whole blood according to standard protocols. Patients with Addison's disease $(n=125)$, Hashimoto's thyroiditis $(n=121)$, Graves' disease $(n=85)$, type 1 diabetes mellitus $(n=252)$ and healthy controls $(n=125)$ were studied for the CYP27B1 intron $6(+2838)$ C/T polymorphism (Genbank accession no. AF072470). The CYP27B1 promoter $(-1260)$ C/A polymorphism (Genbank AB006987) aligned with promoter sequence from Kong et al. (24) was analyzed in 124 patients with Addison's disease, 139 with Hashimoto's thyroiditis, 334 with Graves' disease, 220 with type 1 diabetes mellitus and 320 healthy controls, using polymerase chain reaction followed, for the first polymorphism, by single strand conformation polymorphism (SSCP) analysis, as described previously (25). The amplified fragment of the CYP27B1 promoter $(-1260)$ polymorphism was digested with the restriction enzyme TfiI (New England Bio Labs, Beverly, MA, USA) according to the manufacturer's instructions. Digestion product was separated on $2.5 \%$ agarose gel. The gel was visualized by SYBR green staining and ultraviolet illumination. The two polymorphisms are separated by an interval of $4471 \mathrm{bp}$.

\section{Statistical analysis}

Observed and expected genotype frequencies were compared based on the Hardy-Weinberg equation as well as power calculations performed (based on the observed homozygote/heterozygote frequencies in patients and in controls) using BiAS statistical package version 7.01 (Epsilon, Weinheim, Germany). Patients and controls were compared using allele-wise and genotype-wise $X^{2}$ testing. Probabilities $(P)$ were regarded as significant if $P<0.05$ using BiAS software.

\section{Results}

The observed CYP27B1 intron $6(+2838)$ C/T polymorphism and CYP27B1 promoter $(-1260)$ C/A polymorphism genotype frequencies were in accordance with the Hardy-Weinberg equilibrium in the groups with autoimmune disease as well as in the control group (data not shown). 
Analysis of the CYP27B1 intron $6(+2838) \mathrm{C} / \mathrm{T}$ polymorphism (see Table 1) showed no differences in either of the genotypes between patients with Addison's disease, Graves' disease, type 1 diabetes mellitus and controls $(P=0.2082, P=0.0991, P=0.9285$ respectively). However, significantly more patients with Hashimoto's thyroiditis were homozygous for TT than healthy controls $(64.5 \%$ vs $44.8 \%, P=0.0058)$. Thus, the gene frequency of the allele $T$ was higher in patients with Hashimoto's thyroiditis than in the control group $(79.8 \%$ vs $66.8 \%, P=0.0016$; see Table 1$)$.

The gene typing of the CYP27B1 promoter $(-1260)$ $\mathrm{C} / \mathrm{A}$ polymorphism (Table 2 ) revealed that the $C \mathrm{C}$ genotype was significantly more frequent in patients with Addison's disease, than in healthy controls $(51.6 \%$ vs $39.7 \%$ respectively, $P=0.0062$ ). Patients with Hashimoto's thyroiditis and type 1 diabetes mellitus also had higher frequencies of the allele $C$ than controls $(73.74 \%$ and $74.10 \%$ vs $66.1 \%, P=0.0269$ and $P=0.0062$ respectively; Table 2). However, a borderline association was found for the frequency of the allele $C$ between Graves' disease and controls $(P=0.0581)$, whereas it did not show any difference $(P=0.3354)$ for patients with Addison's disease.
When all patients with an autoimmune disease were considered as one group and compared with the controls, the allele $C$ was significantly more frequent in the group with endocrine autoimmune diseases than in controls $(66.1 \%$ vs $72.15 \%, P=0.0051)$ (data derived from Table 2).

A power calculation was performed for each group and a power of $86 \%, 71 \%, 83 \%$ and $93 \%$ (Addison's disease, Hashimoto's thyroiditis, Graves' disease and type 1 diabetes mellitus respectively) was obtained for the CYP27B1 promoter $(-1260)$ C/A polymorphism and a power of $25 \%, 24 \%, 61 \%$ and $4 \%$ (Addison's disease, Hashimoto's thyroiditis, Graves' disease and type 1 diabetes mellitus respectively) was obtained for the CYP27B1 intron $6(+2838)$ C/T polymorphism.

No linkage was observed between the promoter $(-1260) \quad \mathrm{C} / \mathrm{A}$ and intron $6 \quad(+2838) \quad \mathrm{C} / \mathrm{T}$ polymorphisms.

\section{Discussion}

In the present study, we investigated two CYP27B1 hydroxylase gene polymorphisms in the susceptibility to Addison's disease, Hashimoto's thyroiditis, Graves'

Table 1 Distribution of the CYP27B1 intron 6 (2338 T/C) polymorphism in patients with Addison's disease, Hashimoto's thyroiditis, Graves' disease, type 1 diabetes mellitus and healthy controls.

\begin{tabular}{|c|c|c|c|c|c|c|c|c|c|c|}
\hline & \multicolumn{2}{|c|}{ Controls } & \multicolumn{2}{|c|}{$\begin{array}{l}\text { Addison's } \\
\text { disease }\end{array}$} & \multicolumn{2}{|c|}{$\begin{array}{l}\text { Hashimoto's } \\
\text { thyroiditis }\end{array}$} & \multicolumn{2}{|c|}{$\begin{array}{l}\text { Graves' } \\
\text { disease }\end{array}$} & \multicolumn{2}{|c|}{$\begin{array}{l}\text { Type } 1 \text { diabetes } \\
\text { mellitus }\end{array}$} \\
\hline & $n$ & $\%$ & $n$ & $\%$ & $n$ & $\%$ & $n$ & $\%$ & $n$ & $\%$ \\
\hline \multicolumn{11}{|c|}{ Polymorphism } \\
\hline TT & 56 & 44.8 & 70 & 56 & 78 & 64.5 & 47 & 55.3 & 118 & 46.82 \\
\hline CC & 14 & 11.2 & 11 & 8.8 & 6 & 4.9 & 13 & 15.3 & 28 & 11.11 \\
\hline TC & 55 & 44 & 44 & 35.2 & 37 & 30.5 & 25 & 29.4 & 106 & 42.06 \\
\hline \multicolumn{11}{|c|}{ Gene frequencies } \\
\hline $\mathrm{T}$ & 167 & 66.8 & 184 & 73.6 & 193 & 79.8 & 119 & 76 & 342 & 67.85 \\
\hline C & 83 & 33.2 & 66 & 26.4 & 49 & 20.2 & 51 & 30 & 162 & 32.15 \\
\hline
\end{tabular}

$P$-values are given for the comparison of controls and the patients with the respective disease.

Polymorphism: $P_{\text {Addision }}=0.2082, P_{\text {Hashimoto }}=0.0058, P_{\text {Graves }}=0.0991, P_{\text {Diabetes }}=0.9285$

Gene frequencies: $P_{\text {Addision }}=0.1177, P_{\text {Hashimoto }}=0.0016, P_{\text {Graves }}=0.5592, P_{\text {Diabetes }}=0.8834$

Table 2 Distribution of the CYP27B1 promoter (-1260 C/A) polymorphism in patients with Addison's disease, Hashimoto's thyroiditis, Graves' disease, type 1 diabetes mellitus and healthy controls.

\begin{tabular}{|c|c|c|c|c|c|c|c|c|c|c|}
\hline & \multicolumn{2}{|c|}{ Controls } & \multicolumn{2}{|c|}{$\begin{array}{l}\text { Addison's } \\
\text { disease }\end{array}$} & \multicolumn{2}{|c|}{$\begin{array}{l}\text { Hashimoto's } \\
\text { thyroiditis }\end{array}$} & \multicolumn{2}{|c|}{$\begin{array}{l}\text { Graves' } \\
\text { disease }\end{array}$} & \multicolumn{2}{|c|}{$\begin{array}{c}\text { Type } 1 \text { diabetes } \\
\text { mellitus }\end{array}$} \\
\hline & $n$ & $\%$ & $n$ & $\%$ & $n$ & $\%$ & $n$ & $\%$ & $n$ & $\%$ \\
\hline \multicolumn{11}{|c|}{ Polymorphism } \\
\hline $\mathrm{CC}$ & 127 & 39.7 & 64 & 51.6 & 75 & 53.95 & 169 & 50.59 & 120 & 54.54 \\
\hline $\mathrm{AA}$ & 24 & 7.5 & 15 & 12.09 & 9 & 6.474 & 28 & 8.383 & 14 & 6.363 \\
\hline CA & 169 & 52.8 & 45 & 36.29 & 55 & 39.56 & 137 & 41.01 & 86 & 39.09 \\
\hline \multicolumn{11}{|c|}{ Gene frequencies } \\
\hline $\mathrm{C}$ & 423 & 66.1 & 173 & 69.76 & 205 & 73.74 & 475 & 71.10 & 326 & 74.10 \\
\hline$A$ & 217 & 33.9 & 75 & 30.24 & 73 & 26.26 & 193 & 28.90 & 114 & 25.90 \\
\hline
\end{tabular}

$P$-values are given for the comparison of controls and the patients with the respective disease.

Polymorphism: $P_{\text {Addision }}=0.0062, P_{\text {Hashimoto }}=0.0173, P_{\text {Graves }}=0.0094, P_{\text {Diabetes }}=0.0028$

Gene frequencies: $P_{\text {Addision }}=0.3354, P_{\text {Hashimoto }}=0.0269, P_{\text {Graves }}=0.0581, P_{\text {Diabetes }}=0.0062$. 
disease and type 1 diabetes mellitus. In our population the allele $C$ of the CYP27B1 promoter - 1260 polymorphism was found significantly more often in the group with an autoimmune endocrine disease than in the control group. Based on these results, the CYP27B1 promoter $-1260 \mathrm{C}$ polymorphism is associated with susceptibility to each autoimmune endocrine disease in the German population. These findings complement our observations that VDR polymorphisms are associated with Addison's disease, type 1 diabetes and autoimmune thyroid diseases $(13-15,26)$ and the alternate allele CYP27B1 (-1260) A might confer protection.

We previously reported that the CYP27B1 +2838 $\mathrm{C} / \mathrm{T}$ polymorphism was not associated with susceptibility to thyroid autoimmune disease in our population (23), but the size of the group with Hashimoto's thyroiditis in that publication was small. In the present investigation in a larger patient sample, we find this polymorphism to be associated with Hashimoto's thyroiditis. These results illustrate the importance of larger samples sizes as well as small $P$ values $(27)$ to corroborate the role of markers in susceptibility, in this case, to autoimmune diseases.

Therefore, another component of the vitamin D system appears to be associated with autoimmune endocrine disease. Inflammatory cytokines induce the expression of CYP27B1 in murine macrophages and this induction in macrophages of diabetic NOD mice was shown to be defective (28) corresponding to an increased type 1 diabetes risk. CYP27B1 knockout mice displayed enlarged lymph nodes in the vicinity of the thyroid gland and a reduction in peripheral CD4 + and CD8 + T lymphocytes (29).

Since our findings were obtained in a large sample size, the CYP27B1 gene and its promoter $(-1260)$ $\mathrm{C} / \mathrm{A}$ polymorphism appears to be a candidate gene for genetic susceptibility to autoimmune endocrine diseases. Corresponding to these results are data from a family study of type 1 diabetes mellitus where we have observed an increased transmission rate of allele $C$ of the $(-1260)$ CYP27B1 promoter polymorphism, confirming its role as a susceptibility factor (unpublished data). Our present investigation extends these findings to a larger group of patients and to other autoimmune endocrine diseases. The different regulation of hydroxylase would affect the local abundance of $1,25(\mathrm{OH})_{2} \mathrm{D}_{3}$, and influence the microenvironment through antigen presenting, dendrite and regulatory immune cells.

Since the promoter variant is located in the promoter region of the key enzyme of vitamin D metabolization, it may affect enzyme transcription and thus the rate of final hydroxylation of $1,25(\mathrm{OH})_{2} \mathrm{D}_{3}$.

However, functional investigations on the effect of this polymorphism on macrophage and lymphocyte function in patients and controls are needed to put these findings into perspective.

\section{References}

1 Paulson SK \& Deluca HF. Subcellular location and properties of rat renal 25-hydroxyvitamin D3-1alpha-hydroxylase. Journal of Biological Chemistry $198526011488-11492$.

2 Zehnder D, Bland R, Walker EA, Bradwell AR, Howie AJ, Hewison M \& Stewart PM. Expression of 25-hydroxyvitamin D3-1alphahydroxylase in the human kidney. Journal of the American Society of Nephrology 200010 2465-2473.

3 Zehnder D, Bland R, Williams MC, McNinch RW, Howie AJ, Stewart PM \& Hewison M. Extrarenal expression of 25-hydroxyvitamin D(3)-1alpha-hydroxylase. Journal of Clinical Endocrinology and Metabolism $200186888-894$.

4 Miller WL \& Portale A. Vitamin D 1alpha-hydroxylase. Trends in Endocrinology and Metabolism 200011 315-319.

5 Monkawa T, Yoshida T, Wakino S, Shinki T, Anazawa H, Deluca HF, Suda T, Hayashi M \& Saruta T. Molecular cloning of cDNA and genomic DNA for human 25-hydroxyvitamin D3 1 $\alpha$-hydroxylase. Biochemical and Biophysical Research Communications $1997239527-533$.

6 Mathieu C, Waer M, Laureys J, Rutgeerts O \& Bouillon R. Prevention of autoimmune diabetes in NOD mice by 1,25 dihydroxyvitamin D. Diabetologia $199437552-558$.

7 Fournier C, Gepner P, Sadouk M \& Charreire J. In vivo beneficial effects of cyclosporin A and 1,25-dihydroxyvitamin D3 on the induction of experimental autoimmune thyroiditis. Clinical Immunology and Immunopathology 199054 53-63.

8 Van Etten E, Branisteanu DD, Overbergh L, Bouillon R, Verstufy A \& Mathieu C. Combination of a 1,25-dihydroxyvitamin $\mathrm{D}_{3}$ analog and a bisphosphonate prevents experimental autoimmune encephalomyelitis and preserves bone. Bone 200332 397-404.

9 Hahn HJ, Kuttler B, Mathieu C \& Bouillon R. 1,25-Dihydroxyvitamin D3 reduces MHC antigen expression on pancreatic beta-cells in vitro. Transplantation Proceedings $1997292156-2157$.

10 Thomasset M. Vitamin D and the immune system. Pathology Biology 199442 163-172.

11 Piemonti L, Monti P, Sironi M, Fraticelli P, Leone BE, Dal Cin E, Allavena P \& Di Carlo V. Vitamin $\mathrm{D}_{3}$ affects differentiation, maturation, and function of human monocyte-derived dendritic cells. Journal of Immunology $2000 \mathbf{1 6 4} 4443-4451$.

12 Griffin MD, Lutz W, Phan VA, Bachman LA, McKean DJ \& Kumar R. Dendritic cell modulation by 1alpha, 25 dihydroxyvitamin D3 and its analogs: a vitamin D receptor-dependent pathway that promotes a persistent state of immaturity in vitro and in vivo. PNAS 200198 6800-6805.

13 Pani MA, Knapp M, Donner H, Braun J, Baur MP, Usadel KH \& Badenhoop K. Vitamin D receptor allele combination influence genetic susceptibility to type 1 diabetes in Germans. Diabetes $200049504-507$

14 Ban Y, Ban Y, Taniyama M \& Katagiri T. Vitamin D receptor initiation codon polymorphism in Japanese patients with Graves' disease. Thyroid $200010375-380$.

15 Pani MA, Seissler J, Usadel KH \& Badenhoop K. Vitamin D receptor genotype is associated with Addison's disease. European Journal of Endocrinology 200247 635-640.

16 Maclaren NK \& Riley WJ. Inherited susceptibility to Addison's diseases is linked to human leukocyte antigens-DR3 and/or -DR4, except when associated with type 1 autoimmune polyglandular syndrome. Journal of Clinical Endocrinology and Metabolism 1986 $62455-459$.

17 Huang W, Connor E, Rosa TD, Schatz D, Siverstein J, Crockett S, She JX \& Maclaren NK. Although DR3-DQB1*0201 may be associated with multiple component diseases of the autoimmune polyglandular syndromes, the human leukocyte antigen DR4DQB $1 * 0302$ haplotype is implicated only in beta-cell autoimmunity. Journal of Clinical Endocrinology and Metabolism $1996 \mathbf{8 1}$ 2559-2563.

18 Yu L, Brewer KW, Gates S, Wu A, Wang T, Babu SR, Gottlieb PA, Freed BM, Noble J, Erlich HA, Rewers MJ \& Eisenbarth GS. DRB1*04 and DQ alleles: expression of 21-hydroxylase 
autoantibodies and risk of progression to Addison's disease. Journal of Clinical Endocrinology and Metabolism $199984328-335$.

19 Weetman AP, Zhang L, Tandom N \& Edwards OM. HLA associations with autoimmune Addison's disease. Tissue Antigens $19913831-33$

20 Badenhoop K, Walfish PG, Rau H, Fischer S, Nicolay A, Bogner U, Schleusener H \& Usadel KH. Susceptibility and resistance alleles of human leukocyte antigen (HLA) DQA1 and HLA DQB1 are shared in endocrine autoimmune disease. Journal of Clinical Endocrinology and Metabolism $1995 \mathbf{8 0} 2112-2117$.

21 Donner H, Braun J, Seidl C, Rau H, Finke R, Ventz M, Walfish PG, Usadel KH \& Badenhoop K. Codon 17 polymorphism of the cytotoxic T lymphocyte antigen 4 gene in Hashimoto's thyroiditis and Addison's disease. Journal of Clinical Endocrinology and Metabolism 199782 4130-4132.

22 Kemp EH, Ajjan RA, Husebye ES, Peterson P, Uibo R, Imrie H, Pearce SH \& Weetman AP. Cytotoxic T lymphocyte antigen-4 (CTLA-4) gene polymorphism is associated with autoimmune Addison's disease in English patients. Clinical Endocrinology $199849609-613$.

23 Pani MA, Regulla K, Segni M, Krause M, Hofmann S, Hüfner M, Herwig J, Pasquino AM, Usadel K \& Badenhoop K. Vitamin D $1 \alpha-$ hydroxylase (CYP1 $\alpha$ ) polymorphism in Graves' disease, Hashimoto's thyroiditis and type 1 diabetes mellitus. European Journal of Endocrinology 2002146 777-781.

24 Kong XF, Zhu XH, Pei YL, Jackson DM \& Holick MF. Molecular cloning, characterization, and promoter analysis of the human 25-hydroxyvitamin D3-1alpha-hydroxylase gene. PNAS 1999 $966988-6993$.
25 Smith SJ, Rucka AK, Berry JL, Davies M, Mylchreest S, Paterson CR, Heath DA, Tassabehji M, Read AP, Mee AP \& Mawer EB. Novel mutations in the 1alpha-hydroxylase (P450c1) gene in three families with pseudovitamin D-deficiency rickets resulting in loss of functional enzyme activity in blood-derived macrophages. Journal of Bone and Mineral Research 199914 730-739.

26 McDermott MF, Ramachandran A, Ogunkolade BW, Aganna E, Curtis D, Boucher BJ, Snehalatha C \& Hitman GA. Allelic variation in the vitamin D receptor influences susceptibility to IDDM in Indian Asians. Diabetologia 199740 971-975.

27 Dahlman I, Eaves IA, Kosoy R, Morrison VA, Heward J, Gough SCL, Allahabadia A, Franklyn JA, Tuomilehto J, Tuomilehto-Wolf E, Cucca F, Guja C, Ionescu-Tirgoviste C, Stevens H, Carr P, Nutland S, Mckinney P, Shield JP, Wang W \& Heather J. Parameters for reliable results in genetic association studies in common disease. Nature Genetics $200230149-150$.

28 Overbergh L, Decallone B, Valckx D, Verstuyf A, Depovere J, Laureys J, Rutgeerts O, Saint-Arnaud R, Bouillon R \& Mathieu C. Identification and immune regulation of 25 hydroxyvitamin D 1-alpha-hydroxylase in murine macrophages. Clinical and Experimental Immunology 2000120 139-146.

29 Panda DK, Miao D, Tremblay ML, Sirois J, Farooki R, Hendy GN \& Goltzman D. Targeted ablation of the 25-hydroxyvitamin D 1alpha-hydroxylase enzyme: evidence for skeletal, reproductive, and immune dysfunction. PNAS 200198 7498-7503.

Received 3 March 2004

Accepted 17 May 2004 